\title{
Mature Cystic Teratoma of Spinal Cord in a 16-Year-Old Male: A Case Report
}

\author{
Hiva Saffar ${ }^{1 *}$, Atieh Khorsand ${ }^{1}$, Morteza Faghih Jouibari ${ }^{2}$, Seyed Mohammad Tavangar ${ }^{1}$
}

1. Department of Pathology and Laboratory Medicine, Shariati Hospital, Tehran University of Medical Sciences, Tehran, Iran

2. Department of Neurosurgery, Shariati Hospital, Tehran University of Medical Sciences, Tehran, Iran

Scan to discover online

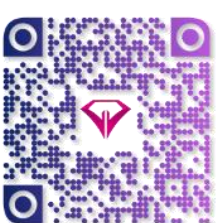

\begin{tabular}{ll}
\hline Main Subjects: \\
Neuropathology \\
\hline
\end{tabular}

Received 29 July 2018;

Accepted 16 Sep 2019;

Published Online 26 Dec 2019;

d.

10.30699/IJP.2019.89854.1849

PMCID: PMC6995675

PMID: $\quad 32095150$

\begin{abstract}
Teratoma is a type of multipotential cell tumor, which includes a mixture of two or three germinal layers of ectodermis, endodermis, and mesodermis. Although neonatal sacrococcygeal teratoma has been frequently reported, its occurrence in older age is not common. In this study, we report a rare case of spinal intradural mature cystic teratoma in a 16-year-old male, emphasizing on considering this unusual condition in differential diagnosis of spinal cord cystic tumors.
\end{abstract}

KEYWORDS: Adolescent, Spinal cord, Teratoma

Corresponding Information:

Hiva Saffar, Associate Professor of Clinical and Anatomical Pathology, Department of Pathology and Laboratory Medicine, Shariati Hospital, Tehran University of Medical Sciences, Tehran, Iran Email: Hsaffar@sina.tums.ac.ir

Copyright ( $(2020$. This is an open-access article distributed under the terms of the Creative Commons Attribution- 4.0 International License which permits Share, copy and redistribution of the material in any medium or format or adapt, remix, transform, and build upon the material for any purpose, even commercially.

\section{Introduction}

Teratoma is a type of multipotential cell tumor, which includes a mixture of multiple germinal layers $(1,2)$. Spinal cord teratoma, especially in adult patients, is extremely rare (3) and constitutes about $0.1 \%$ to $0.5 \%$ of all spinal tumors $(3,4)$. The first teratoma case was described by Virchow in 1863 . Then, 25 years later, Gowes and Horsleng reported another case of this group (4). In this study, we report a rare case of spinal intradural mature cystic teratoma (MCT) in a 16-yearold male.

\section{Case Report}

A 16-year-old male with history of radiation to both lower limbs, especially the right side, is presented with progressive thoracolumbar pain of 1.5 years duration. His complaints were aggravated by standing and walking. Motor forces were full and there was no sensory deficit. Deep tendon reflexes were within normal limits but plantar reflex was upward in right side.

The magnetic resonance imaging (MRI) results revealed an intradural extra medullary lobulated cystic lesion measuring $21 \times 21 \mathrm{~mm}$ at T12 level. Conus was pushed anteriorly. Mild canal dilation was seen and discs were intact (Figure 1).

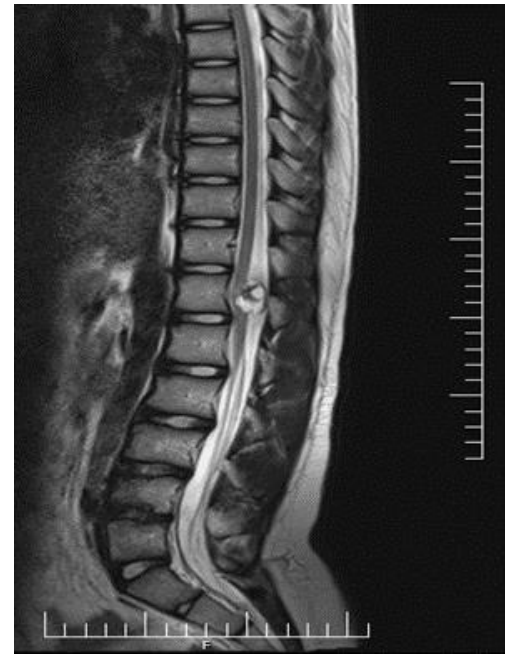

Fig. 1. MRI of spinal cord

The patient underwent surgery and after T10 to L2 laminectomy and dural opening, the lesion was detected, that was attached to posterior of conus medullaris. It was firm and yellowish and contained some cystic areas filled with xanthomatous fluid. There was no cleavage plane between lesion and spinal cord. Piecemeal resection was performed and finally all parts of lesion were removed except a thin layer that was attached to spinal cord. 
The samples received as fragmented soft tissue in $10 \%$ buffered formalin. On histologic examination, the excised lesion revealed elements of various germ cell layers including differentiated components of squamous epithelial nests with hair shafts, nerve bundles, fibrofatty tissue, skeletal muscle fibers, and mucous glands (Figure 2). Also, cystic structure lined by cuboidal cells was identified. The case was diagnosed as MCT.
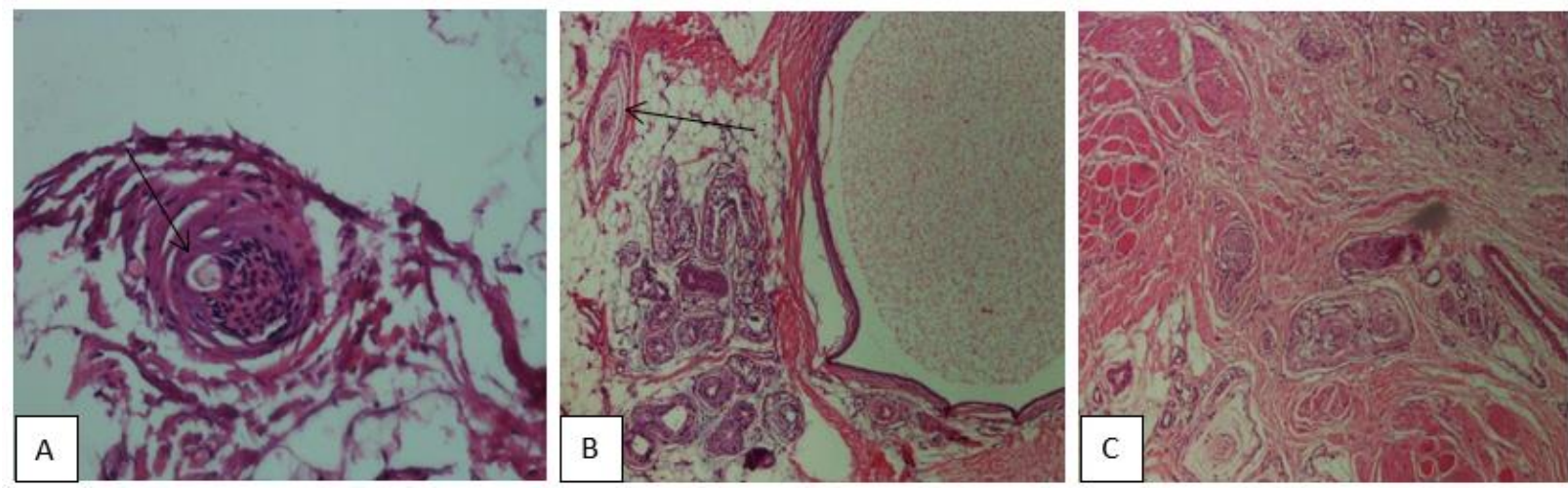

Fig. 2. A: Squamous epithelial nest including hair shaft (arrow). B: Mucus glands embedded in adipose background as well as nerve bundle (arrow). C: striated muscle fibers and nerve bundles (H\&E staining)

\section{Discussion}

Teratomas are a kind of tumor composed of multipotential cells formed by normal organogenesis, producing tissues which represent a mixture of two or three germinal layers of ectodermis, endodermis, and mesodermis (5). The tumor is categorized as mature and immature (malignant) (5).

Although neonatal sacrococcygeal teratoma (SCT) has been frequently reported, occurrence in older age is not common. As our case, most reported cases have been located in the lower thoracic and thoracolumbar region (5).

In a report by Poezem et al. $(4,6), 31$ out of 83 cases were intramedullary type and most others were intradural extramedullary lesions. Our case was a 16year-old male with intradural extra medullary lobulated cystic lesion at T12 level.

MRI is considered as the gold standard technique which can not only determine the location, but also reveal the data about the degree of spinal cord involvement (4).

The morphologic presentation varies in the MRI regarding the location. Intradural tumors are commonly oval or lobulated (like our case) whereas extradural ones are frequently dumbbell shaped (1).

Most cases in the literature present with weakness of extremity, sensory change or reflex abnormalities, which can vary according to tumor location (4). Our patient had no focal neurological deficit except for upward plantar reflex in right side.

Various theories have been suggested concerning the origin of the tumor development $(1,2,5)$. Among them the most accepted is misplacement of primordial germ cells in to the dorsal midline during their normal migration from primitive yolk sac to gonadal ridges $(2,5,7)$.

Additionally, supporting the above theory, teratomas are believed to be associated with dysraphic defects such as hair patch, dimples, etc. located at the median plane of the body (5). However, our case was normal.

Moreover, $\alpha$-FP and $\beta$-hCG have been known as tumor markers in germ cell tumors. They are sensitive and specific, helping in primary diagnosis, staging or monitoring of the therapeutic response. However, it should be mentioned that pure mature teratomas usually do not secret these products (8).

Total surgical resection is the treatment of choice $(2,4)$. But adhesion to surrounding neural tissue sometimes makes it impossible $(2,4)$. While some authors believe that subtotal resection increases the chance of recurrence $(4,9,10)$, some other researchers have expressed that, due to extremely slow growth of tumor, there is no risk for recurrence of symptoms even over many years (2).

Adjuvant therapy after surgery is controversial due to rare occurrence of tumor and limited experience for management, but it is believed that it should be decided according to histological features (5).

Our patient did not show any immature components or malignant histologic features and he was in good condition two years after the surgery.

Another important point to be mentioned is that the cyst content should not be spilled into intradural space because of probable side effects such as chemical meningitis with or without obstructive hydrocephalous (4).

Finally, here we reported a rare case of spinal MCT devoid of histologic features of malignancy who responded to surgical resection without evidence of recurrence after 16 months.

\section{Acknowledgements}

The authors would like to thank Mrs. Leila Mohebbi for her technical support 


\section{Conflict of Interest}

The authors declared that there is no conflict of interest regarding the publication of this article.

\section{References}

1. Li Y, Yang B, Song L, Yan D. Mature teratoma of the spinal cord in adults: An unusual case. Oncology letters. 2013 Oct 1;6(4):942-6. [DOI:10.3892/ol.2013.1519] [PMID] [PMCID]

2. Nonomura Y, Miyamoto K, Wada E, Hosoe H, Nishimoto $\mathrm{H}$, Ogura H, Shimizu K. Intramedullary teratoma of the spine: report of two adult cases. Spinal Cord. 2002 Jan;40(1):40. [DOI:10.1038/sj.sc.3101247] [PMID]

3. Kharosekar HU, Naik H, Velho V. Mature cystic teratoma of dorsal spinal cord in adult: An unusual lesion. Asian journal of neurosurgery. 2018 Jan;13(1):140. [DOI:10.4103/17935482.181132] [PMID] [PMCID]

4. Sung KS, Sung SK, Choi HJ, Song YJ. Spinal intradural extramedullary mature cystic teratoma in an adult. Journal of Korean Neurosurgical Society. 2008 Nov;44(5):334. [DOI:10.3340/jkns.2008.44.5.334] [PMID] [PMCID]

5. Ak H, Ulu MO, Sar M, Albayram S, Aydın S, Uzan M. Adult intramedullary mature teratoma of the spinal cord: review of the literature illustrated with an unusual example. Acta neurochirurgica. 2006 Jun 1;148(6):663-9. [DOI:10.1007/s00701-006-0755-z] [PMID]
6. Poeze M, Herpers MJ, Tjandra B, Freling G, Beuls EA. Intramedullary spinal teratoma presenting with urinary retention: case report and review of the literature. Neurosurgery. $\quad 1999 \quad$ Aug 1;45(2):379-85 [DOI:10.1097/00006123-199908000-00038] [PMID]

7. Al-Sarraj ST, Parmar D, Dean AF, Phookun G, Bridges LR. Clinicopathological study of seven cases of spinal cord teratoma: a possible germ cell origin. Histopathology. 1998 Jan;32(1):51-6. [DOI:10.1046/j.1365-2559.1998.00324.x] [PMID]

8. Sandoval JA, Malkas LH, Hickey RJ. Clinical significance of serum biomarkers in pediatric solid mediastinal and abdominal tumors. International journal of molecular sciences. 2012 Jan;13(1):1126-53. [DOI:10.3390/ijms13011126] [PMID] [PMCID]

9. Makary R, Wolfson D, Dasilva V, Mohammadi A, Shuja S : Intramedullary mature teratoma of the cervical spinal cord at C1-2 associated with occult spinal dysraphism in an adult. $\begin{array}{llll}\text { JNeurosurg } & \text { Spine 6: 579-584, } 2007\end{array}$ [DOI:10.3171/spi.2007.6.6.12] [PMID]

10. Nonomura Y, Miyamoto K, Wada E, Hosoe H, Nishimoto $\mathrm{H}$,Ogura $\mathrm{H}$, et al : Intramedullary teratoma of the spine: report of two adult case. Spinal Cord $40:$ 40-43, 2002. [DOI:10.1038/sj.sc.3101247] [PMID]

\section{How to Cite This Article}

Saffar, H., khorsand-rahimzadeh, A., Faghihjouibari, M., Tavangar, S. Mature Cystic Teratoma of Spinal Cord in A 16-Year-Old Male: A Case Report. Iranian Journal of Pathology, 2019; 15(1):45-47.

doi: 10.30699/ijp.2019.89854.1849 